\title{
SORPTION KINETICS OF ISOPROTURON AND ASSESSMENT OF ITS ECOTOXICITY ON Lemna minor
}

\section{Quazi Forhad Quadir* and Atiqur Rahman}

Department of Agricultural Chemistry, Faculty of Agriculture

Bangladesh Agricultural University, Mymensingh 2202, Bangladesh

*Corresponding Author: Quazi Forhad Quadir, E-mail: qfq@bau.edu.bd

\section{ARTICLE INFO \\ ABSTRACT}

Received:

23.09.2014

Accepted:

10.12.2014

Online:

27.12.2014

Key words:

Sorption

Kinetics

Isoproturon

Ecotoxicity

Lemna minor
The study was carried out to investigate the ecotoxicity of Isoproturon on Lemna minor and the interaction of the $\mathrm{EC}_{50}$ value of the chemical with sorption behaviour of the chemical in soil. The sorption isotherms $\left(\mathrm{K}_{\mathrm{f}}\right.$ and $\mathrm{Koc}$ ) for Isoproturon were determined for three different soils having various organic carbon and clay content. $\mathrm{EC}_{50}$ for Lemna was determined both with and without soil. Both the Freundlich adsorption coefficient $\left(\mathrm{K}_{\mathrm{f}}\right)$ and normalized sorption coefficient (Koc) values varied with different types of soil. There was moderate correlation between the log $K_{f}$ and $\log$ Koc existed. The regression study revealed a strong relationship between $\log \mathrm{K}_{\mathrm{oc}}$ and organic carbon and between log $\mathrm{K}_{\mathrm{oc}}$ and soil clay content. There $\mathrm{EC}_{50}$ value for Lemna grown with soil was higher than that grown without soil. However, the difference was statistically insignificant. Greater degree of inconsistency in various data suggests the reiteration of the study.

To cite this article: QF Quadir and A Rahman, 2014. Sorption kinetics of isoproturon and assessment of its ecotoxicity on Lemna minor. Res. Agric., Livest. Fish. 1(1): 13-18.

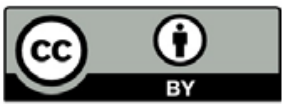

This article is an open access article licensed under the terms of the Creative Commons Attribution License.

www.agroaid-bd.org/ralf, e-mail: editor.ralf@gmail.com 


\section{INTRODUCION}

Isoproturon (IPU) is a widely used phenylurea derived systemic herbicide [3-(4isopropylphenyl)-1, 1-dimethylurea] for the control of annual grasses and broad-leaved weeds in agricultural fields. This herbicide is specific for monocots and mainly inhibits the electron transport in photosystem II and thereby disrupts the photosynthetic pathway of the target plant (Arnaud et al., 1994). It is one of the most common herbicide species, applied and to be found in water samples. Though IPU has a short environmental half-life (soil DT ${ }_{50}$ 6-28 d) (Tomlin, 2001); reports on frequent finding of IPU in both surface and ground water at concentrations exceeding the European Union limit for drinking water $\left(0.1 \mu \mathrm{g} \mathrm{liter}{ }^{-1}\right)$ (Johnson et al., 2001; Spliid and Køppen, 1998; Stangroom et al., 1998) has arisen the issue of environmental concern.

Sorption is one of the soil phenomena which directly affects the retention, volatilization, biodegradation, transport of organic chemicals in soil and uptake by plants. Therefore, the sorption constant is an important parameter used in a variety of models for predicting the ecotoxicity of organic chemicals entering in the environment (Wu et al., 2000; Blume and Ahlsdorf, 1993). Chiou et al. (1979) and Green and Karickhoff (1990) observed that the value of Koc for a compound measured in different soils approach towards a constant, and thus the $\mathrm{K}_{\mathrm{f}}$ value for any given compound is closely related to the organic carbon constant of the soil. Sorption behaviour of a chemical in soil may assist in predicting the toxicity in the natural environmet. Because, it help simulates the actual amount of exposure of an organism in the environment. Since IPU is a major herbicide found in the aquatic ecosystem, duckweed (Lemna minor) was selected as the test organism for assessing the IPU's ecotoxicity in the aquatic environment. The present research was undertaken to determine the toxicity $\left(E_{50}\right)$ of isoproturon on aquatic test plant duckweed (Lemna minor) as well as the influence of soil sorption of the herbicide on the same.

\section{MATERIALS AND METHODS}

\section{Preparation of standard IPU solutions}

From IPU stock solution (0.1014 $\mathrm{mg} \mathrm{A.I.} \mathrm{ml}^{-1}$ in methanol), 5 different standard solutions (viz. 0.01, 0.03, 0.06, 0.1 and $0.2 \mathrm{mg} \mathrm{l}^{-1}$ ) were prepared in Swedish Standard (SIS) Lemna growth medium as described in the OECD guideline 221 (OECD,2002).

\section{Setting IPU sorption experiment}

The sorption of experiment was carried out using three different soils in a batch-slurry system with five sorbate concentrations (as mentioned above). The organic carbon and clay contents of the test soils are shown in Table $1.10 \mathrm{~g}$ of air dried soil were weighed into a polypropylene centrifuge bottle and mixed with $20 \mathrm{ml}$ standard IPU solutions. At least three replicates were run for the sorption experiment. A control was also carried out using the top concentration (i.e. $0.2 \mathrm{mgl}^{-1}$ ) without soil. The tubes were placed in end-over-end shaker for 16 hrs.

Table 1. Organic carbon and clay content of test soils

\begin{tabular}{|ccc|}
\hline Soil & OC content (\%) & Clay content (\%) \\
\hline Soil A & 2.6 & 34 \\
Soil B & 3.4 & 59 \\
Soil C & 1.9 & 16 \\
Soil D & 4.1 & 65 \\
\hline
\end{tabular}




\section{Sampling of the sorption study}

After shaking the centrifuge tubes were removed from the shaker and allowed to stand for about one hrs and then the liquid supernatant were decanted into glass sample tubes. For the ease of chemical analysis by HPLC, the control and the three lower concentrations were extracted and concentrated in methanol by Solid Phase Extraction (SPE) method using SPE cartridges and transferred to glass sample vial. The concentrations of IPU in the extracted sample and the two unextracted higher samples were then determined by HPLC. Using the peak area data obtained from HPLC concentrations in the test samples were calculated.

\section{Lemna Growth Inhibition Test}

The Lemna growth inhibition experiment was conducted in two batches with five replications. The first set was prepared taking only the standard IPU solutions $(20 \mathrm{ml})$ in a 250 $\mathrm{ml}$ conical flask (i.e. without soil). The second set of ecotoxicity test was undertaken by taking $15 \mathrm{~g}$ of soil D in $60 \mathrm{ml}$ of each standard IPU solutions and then stirred to mix the soil and solution well. In both batches of conical flasks 2-3 Lemna colonies were placed and photographed before incubation in a plant growth cabinet for 2 week $\left(20^{\circ} \mathrm{C}, 18 \mathrm{hrs}\right.$ light, $8 \mathrm{hrs}$ dark). After 2 weeks, photographs for the batches without soil were taken. For the rest, frond numbers were counted to determine the growth of Lemna.

Table 2. Mean $\mathrm{K}_{\mathrm{f}}, \mathrm{nf}$ and $\mathrm{K}_{\mathrm{oc}}$ values for different soils

\begin{tabular}{|cccc|}
\hline Soil & $\mathbf{K}_{\mathbf{f}}\left(\mathbf{m l ~}^{-\mathbf{1}}\right)$ & $\mathbf{n f}(-)$ & Koc \\
\hline Soil A & 1.20 & 0.68 & 46 \\
Soil B & 0.94 & 0.87 & 28 \\
Soil C & 1.17 & 0.75 & 61 \\
Soil D & 1.85 & - & 59 \\
\hline
\end{tabular}

\section{Growth rate estimation}

Growth of Lemna was determined using both area of fronds and change in frond numbers. The areas of colonies were determined using the image analysis software Image $\mathrm{J}$. It was done after converting the images at 8-Bits in a binary format. The area (in $\mathrm{cm}^{2}$ ) covered by the fronds was measured by analyzing particles using a fixed length (rular). Then inhibition rate $(I)$ was calculated using the following formula,

Where,

$$
I=\frac{A_{c}-A_{t}}{\mathrm{~A}_{c}} \times 100
$$

$A c=\ln ($ final area of the control) - In (starting area of the control)

At $=\ln$ (final area of the treated Lemna) $-\ln$ (starting area of the treated Lemna)

$I=\%$ inhibition in growth

The computation of the growth rate using the frond number was done by the following equation,

Where,

$$
G R=\frac{\ln \left(N_{j}\right)-\ln \left(N_{i}\right)}{t_{j}-t_{i}}
$$

$G R=$ Average specific growth rate

$N_{i}=$ No. of fronds determined at time i

$N_{j}=$ No. of fronds determined at time j

$t_{i}=$ Moment time for start of the period

$t_{j}=$ Moment time for end of the period

The inhibition data was then used in the Probit programme to develop concentrationresponse relationship. The $\mathrm{EC}_{50}$ of IPU was determined both excluding and including soil data set. 


\section{Measurement of sorption parameters}

The Freundlich adsorptions constant $\left(\mathrm{K}_{\mathrm{f}}\right)$ was calculated by putting the soil sorption data in the solver function in the MS Excel and using the following equation:

Where,

$$
C_{s}=K_{f} C_{e}^{1 / n}
$$

$C_{s}$ is the concentration on soil at the end of experiment $(\mathrm{mg} / \mathrm{g})$;

$C_{e}$ is concentration in the liquid phase at the end of experiment $(\mathrm{mg} / \mathrm{ml})$;

$K_{f}$ is the soil-water partition coefficient $(\mathrm{ml} / \mathrm{g})$; and

$1 / n$ is the Freundlich coefficient.

\section{Measurement of Koc values}

Koc values for Soil A, B and C were calculated using the following formula,

Where,

$$
K_{o c}=\frac{K_{f} \times 100}{\% O C}
$$

Koc is the normalized sorption coefficient;

$K_{f}$ is the Freundlich sorption coefficient; and

$O C$ is organic matter content of soil (\%).

From the mean $K_{o c}$ value of soil A, B and C, the $K_{f}$ for soil D was also estimated (Table 2).

\section{Statistical analysis}

The collected data for $\mathrm{EC}_{50}$ values and the sorption data at the end were analyzed statistically using t-Test with the help of SPSS data analysis software.

\section{RESULTS AND DISCUSSION}

\section{Sorption coefficients}

The values of $K_{f}$, nf and $K_{o c}$ for IPU in three different soils is given in Table 2. The $K_{f}$ value ranges from 0.94 to 1.2 . While the Koc values varied widely, ranges between 28 and 61. In all three cases the nf value is less than 1 . This indicated that the relationship between $\mathrm{K}_{\mathrm{f}}$ and $\mathrm{Koc}$ is nonlinear; it is rather exponential.

The $\mathrm{K}_{\mathrm{f}}$ value indicates the sorption behaviour of organic chemicals in soil system. Here the $\mathrm{K}_{\mathrm{f}}$ for different soil is not dispersed widely and the value is comparatively low. It indicates the less tendency of Isoproturon to be sorbed with the soil. Isoproturon is not considered to be sorbed to soil to a large extent compared with other herbicides as reported by other investigators (Singh et al., 2001). However, the reports on the $\mathrm{K}_{\mathrm{f}}$ for Isoproturon is much greater and can be as high as 3.84 (Johannesen et al., 2003). Inconsistent values obtained from different replicated soil samples may be contributed toward this low value of $\mathrm{K}_{\mathrm{f}}$. The lower range of $\mathrm{K}_{\mathrm{f}}$ indicates that it differs less from soil to soil and may be used to calculate the sorption behaviour of a chemical in a different soil with less uncertainty.

On the other hand, the Koc value had a greater range and varied with the soil organic carbon content. The greater range Koc may make it unpredictable to assess the sorption behaviour of a chemical in a separate soil. Actually, the organic matter appears to be a function of a partition medium for organic chemicals in solution. Hence it varies very sharply for the variation in organic carbon content.

The regression studies between different sorption coefficients $\left(K_{f}\right.$ and $\left.K_{o c}\right)$ and $O C$ and clay content of soil as shown in Figure 1 (a) - (d) revealed a strong correlation between log Koc and \% OC $\left(R^{2}=0.986\right)$ as well as Koc and \% clay $\left(R^{2}=0.996\right)$. On the other hand, the relationship was moderate between $\log K_{f}$ and $\log K_{o c}\left(R^{2}=0.643\right)$. This is, rather inconsistent with the results demonstrated by Wu et al. (2000) and Johannesen et al. (2003). They reported a strong relationship between the $\mathrm{K}_{\mathrm{f}}$ and $\mathrm{Koc}$ values of IPU. 
Table 3. Mean and standard deviation for $\mathrm{EC}_{50}$ values in presence and absence of soil D

\begin{tabular}{|l|c|c|}
\hline Treatment & Mean & Standard deviation \\
\hline Without soil & 0.12 & 0.073 \\
With soil & 0.17 & 0.053 \\
\hline
\end{tabular}

In the Lemna growth study, for most cases highest inhibition in growth was observed highest at the highest concentration and the lowest at control and $0.01 \mathrm{mg} \mathrm{t}^{-1}$ level (see Appendix). The $\mathrm{EC}_{50}$ value for Lemna using soil or without soil was found 0.171 and 0.121 $\mathrm{mg} \mathrm{l}^{-1}$ (Table 3). It is noticeable that the value is greater in with soil treatment than the treatment lacks soil. However, statistical analysis revealed no significant difference between the two data sets. The reason behind may be the values dispersed very widely.

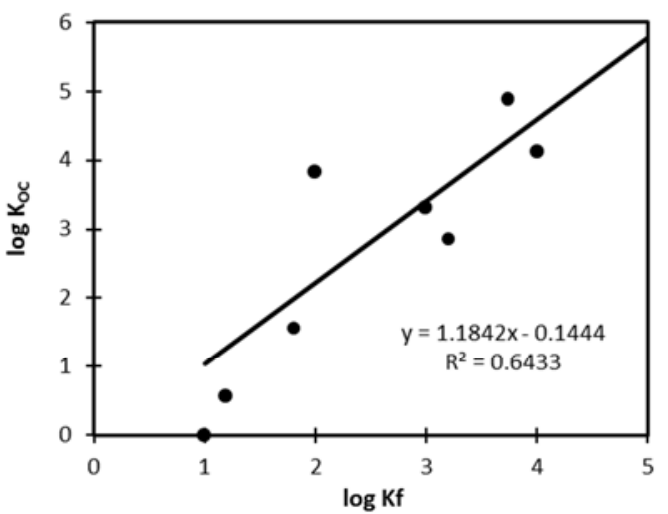

(a)

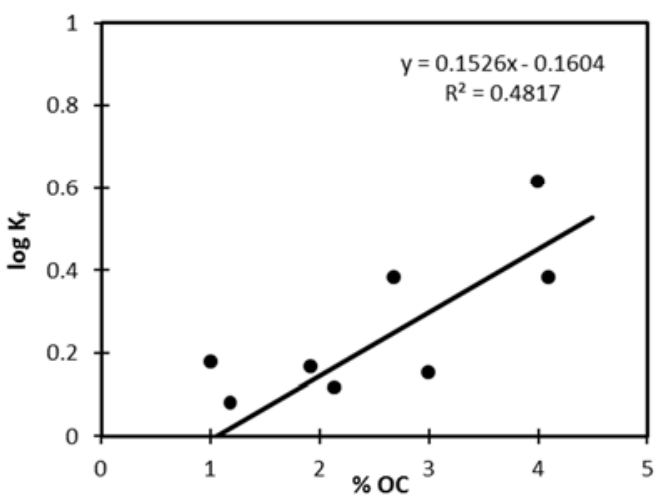

(b)

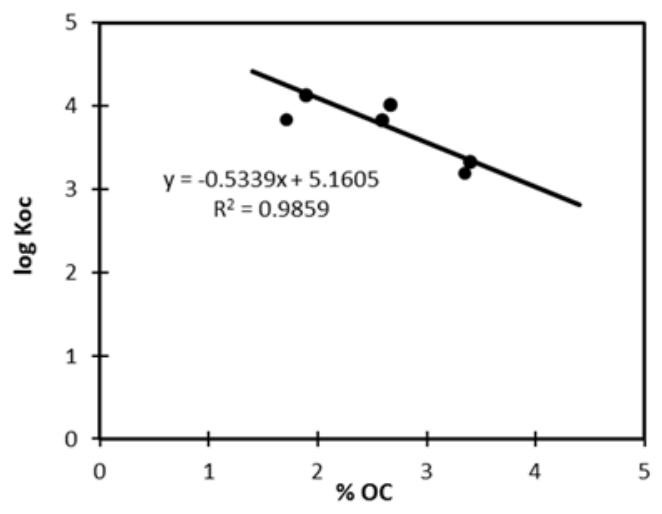

(c)

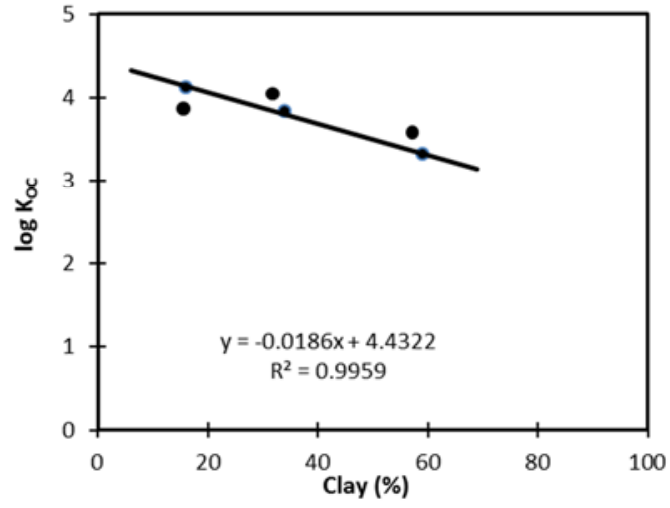

(d)

Figure 1. Regression for (a) soil sorption data (log Koc values) on the Freundlich sorption coefficient ( $\log \mathrm{K}_{\mathrm{f}}$ values) for Isoproturon in different soils; (b) soil organic carbon (OC) and Log $\mathrm{K}_{\mathrm{f}}$, (c) OC and Log Koc; and (d) soil clay content and log Koc. Ecotoxicity assessment of IPU on Lemna

The comparatively lower mean $\mathrm{EC}_{50}$ value in treatment lacking soil is presumable. Because it is assumed that some portion of the IPU will be adsorbed to the soil adsorption sites (organic matter and clays). Hence, the toxicity of the herbicide towards Lemna will be buffered to some extent. Because organic matter is a major sorbent of organic chemicals (Chiou, 1989 and Luthy et al., 1997).

A fair degree of irregularity was observed in the various data sets. And this strongly indicated the errors might have been occurred during the conduction of the study. A second attempt may be undertaken to assess the results of the present study.

\section{COMPETING INTEREST}

The authors declare that they have no competing interests. 


\section{REFERENCES}

1. Arnaud L, G Taillandier, M Kaouadji, P Ravanel and M Tissut, 1994. Photosynthesis inhibition by phenylureas: a QSAR Approach. Ecotoxicology and Environmental Safety, 28: 121-133.

2. Blume HP and B Ahlsdorf, 1993. Prediction of pesticide behavior in soil by means of simple field tests. Ecotoxicology and environmental safety, 26: 313-332.

3. Chiou CT, 1989. Theoretical considerations of the partition uptake of nonionic organic compounds by soil organic matter. In Reactions and movements of and organic chemicals in soils, Eds., Sawhey BL and K Brown. ASA and SSSA, Madison, WI. pp: 1-29.

4. Chiou CT, LJ Peters and VH Freed, 1979. Physical concept of soil-water equilibria for nonionic organic compounds. Science, 206:831-832.

5. Green RE and SW Karickhoff, 1990. Sorption estimates for modeling. In Pesticides in the soil environment: Processes, impacts, and modeling. Eds., Cheng HH. SSSA Book Ser. 2. SSSA, Madison, WI. B.L. pp: 79-101.

6. Johannesen H, SR Sørensen and J Aamand, 2003. Mineralization of Soil-Aged Isoproturon and Isoproturon Metabolites by Sphingomonas sp. Strain SRS2. Journal of Environmental Quality, 32:1250-1257.

7. Johnson AC, TJ Besien, CL Bhardwaj, A Dixon, DC Gooddy, AH Haria and C White, 2001. Penetration of herbicides to groundwater in an unconfined chalk aquifer following normal soil applications. Journal of Contaminant Hydrology, 53:101-117.

8. Luthy R, G Aiken, M Brusseau, S Sunningham, P Gschwend, M Reinhard, S Traina, W Weber and J Westall, 1997. Sequestration of Hydrophobic Organic Contaminants by Geosorbents. Environmental Science \& Technology, 31: 3341-3347.

9. OECD, 2002. OECD Guidelines for the testing of chemicals- Revised proposal for a new guideline 221 (Lemna sp. Growth Inhibition Test). Organisation for Economic Co-operation and Development. http://www.oecd.org/dataoecd/16/51/1948054.pdf

10. Rønhede S, Bo Jensen, S Rosendahl, BB Kragelund, RK Juhler and J Aamand, 2005. Hydroxylation of the Herbicide Isoproturon by Fungi Isolated from Agricultural Soil. Applied and Environmental Microbiology, 71(12):7927-7932

11. Singh N, H Kloeppel and W Klein, 2001. Sorption behaviour of metolachlor, isoproturon nd terbuthylazine in soils. Journal of Environmental Science and Health. Part B, 36:397-407.

12. Spliid NH and B Køppen, 1998. Occurrence of pesticides in Danish shallow ground water. Chemosphere, 37:1307-1316.

13. Tomlin CDS, 2001. The Pesticide Manual, 12th edition. The British Crop Protection Council, UK.

14. Wu H, HP Blume, L Rexilius, M Folschow and U Schleuss, 2000. Sorption of atrazine, 2, 4$\mathrm{D}$, nitrobenzene and pentachlorophenol by urban and industrial wastes. European Journal of Soil Science, 51: 335-344. 